\title{
Das mônadas de Leibniz à educação estética de Schiller
}

\author{
Roberison Wittgenstein Dias Silveira
}

\section{Resumo:}

Partindo da proposta ontológica de Leibniz, a ideia de perfeição dá origem à discussão estética germânica. O grande questionamento é se o gosto está ligado a uma concepção de perfeição inerente à realidade ou se é o resultado da dinâmica dos sentidos, responsáveis pelas sensações. Reformulando a concepção estética moderna, Kant não concebe nenhuma validade de coisaem-si para o gosto, ele não está nas coisas nelas mesmas, mas antes na maneira de operar da faculdade de julgar reflexiva. Reconhecendo esta nova perspectiva, e encontrando nela lacunas no que diz respeito à aproximação entre razão e sensibilidade, Schiller propõe uma nova criação da estética como modelo de formação do homem.

Palavras-chave: Perfeição. Educação. Estética.

\begin{abstract}
:
Starting from the ontological proposal of Leibniz, the idea of perfection gives rise to the German aesthetic discussion. The great question is whether taste is tied to a conception of perfection inherent in reality or whether it is the result of the dynamics of the senses, responsible for sensations. Reformulating the modern aesthetic conception, Kant no conceives validity of thing-in-itself for pleasure, it is not in the things themselves, but rather in the way of operating the faculty of judging reflexive. Recognizing this new perspective, and finding in it gaps with respect to the approximation between reason and sensibility, Schiller proposes a new aesthetics as a model of the formation of man
\end{abstract}

Keywords: Perfection. Education. Aesthetics. 


\section{INTRODUÇÃO}

Neste artigo traremos uma reflexão que se detém nos desafios estéticos alemães do século XVIII, avançando na solução kantiana do problema e na maneira pela qual o legado inicial da Crítica do Juízo se estende até Schiller. O intuito principal consiste em mostrar a reflexão de gosto como uma solução inovadora do conhecimento, representada pela unidade sensível-racional, chegando à educação estética.

Antes de qualquer coisa peço que reflitam introdutoriamente sobre o tema da estética, que meditem na questão do gosto e dos prazeres. Detendo neles sua reflexão, breve enfrentará o problema que é central em nossa discussão: como e de que maneira as predileções e prazeres se dão? São eles o resultado de uma condição subjetiva ou são inerentes ao objeto observado? Desse ponto, veremos juntos em que momento as volições do belo, do prazer e do desprazer pareceram encaminhar conceitos capazes de expressar e pôr em dúvida o que de certa forma simplesmente existia. Se observarmos com cuidado, há um certo debate ontológico de base na questão estética, afinal, quando se deposita o primado no objeto em si mesmo, assentimos com alguma validade objetiva do gosto; doutro modo, quando concordamos que o prazer e o desprazer são subjetivos, ensaiamos passos sensíveis ou abstratos na leitura estética. Nossa empreitada começa, então, onde haveria de terminar, no valor fundamental da premissa aceita e, consequentemente, na redefinição deste fundamento na consolidação do debate estético. Dito de outro modo, a resposta ontológica está na base da definição de gosto, apontar seu direcionamento significa se apoderar das ferramentas conceituais pelas quais o problema estético será proposto e, consequentemente, a forma como será solucionado. É evidente que existem divergências que se interpõem na questão do gosto antes de uma redefinição total dos seus paradigmas ontológicos. Não podemos deixar de observar que esta modificação ontológica é uma coisa viva; suas redefinições não caminham numa mão única, partindo do sistema filosófico para o domínio 
fático. $\mathrm{Na}$ verdade, este campo dos acontecimentos e divergências, no nosso caso estéticas, fomenta novas perguntas e, portanto, novas respostas. Não há um engessamento das estruturas de base e, construí-las é um processo contínuo pelo qual a compreensão da realidade apreende a mudança, transformando-se.

Mas vale perguntar: será que a elucidação racional da estética é o melhor caminho, quer dizer, esta será a ferramenta mais apropriada para enfrentar as armadilhas impostas pela razão no trato das coisas sentidas? Suspeitaria mal aquele que antecede à razão a causa da verdade sobre o gosto? Será que é possível fazer algum juízo de gosto diante do desafio estético sem que passe pelo pensamento, ao menos não de maneira formal? Não nos parece, examinando com cuidado, que a tarefa de nos apoderarmos dos conceitos de gosto consiste em abandoná-los? Não é certamente a estética uma fuga dos limites racionais e, como tal, uma coisa cuja investigação se torna proibitiva pela via racional de exposição? Vale insistir nesse ponto: como a estética lida com a sensibilidade sem dispensar a razão? Há um esforço contínuo e operante que amarra aquilo que ascende da alma com aquilo que se sabe sobre ela. Ah, quanta coisa não se fez perdida por não saber-se justificar! A estética, assim entendida, representa o paradoxo de todo o tempo; no preciso momento em que se exprime racionalmente, deixa de validar-se a si pelo que é: prazer ou desprazer, gosto ou desgosto, belo ou feio etc. Alguém certamente responderá que não se trata de uma coisa tão simples ou binária, mas vale insistir: será que o apego à razão pode de fato ser abandonado por completo? Pode-se medir com cuidado estas sentenças, demonstrando que, ardendo ou não de paixões em nosso coração, há sempre uma mente operante, capaz de lidar com os estímulos e os representar corretamente (se não entrar em conflito com a própria ideia de correto)? O certo não nos pareceria mais uma condição abstrata do que efetivamente real? E se é assim, quais são os impactos da estética no preciso lugar que a concebemos? Será definitivamente encontrado no meio termo entre razão e sensibilidade? 
Responder a todos estes questionamentos nos remete aos séculos XVII, XVIII e início de XIX, cenário no qual as impressões da sensibilidade começaram a prevalecer no assentimento do gosto. A grande disputa entre razão e sensibilidade, acompanhada da necessidade central de responder à questão ontológica colocaram os entraves para o enfrentamento da questão estética. O papel da mente e do mundo pareciam desconexos, de forma que se encontrava numa parte um fundamento e noutro o desalento de tê-lo perdido. Em outras palavras, havia uma discussão geral sobre se o gosto residia na mente ou se era efetivo, real, como atributo objetivo daquilo que se observa. Nesse cenário, questionar a mente ou validar seu conteúdo se tornou a moeda de troca de toda a discussão. Para entendê-la em seu sentido mais amplo, iniciamos nossa investigação no que se pode chamar de primórdios da estética moderna, ao menos na ainda fragmentada Alemanha. Nomes como os de Leibniz, Wolff, Baumgarten, Meier, Mendelssohn, Sulzer e Kant são responsáveis pelo sentido de toda esta conversa filosófica e os rumos que tomaram a contemplação da arte e do caráter central do gênio como o elemento de ligação da razão desinteressada. Nesse contexto, o resgate da abordagem dualista no final do século XVIII e no início do XIX trará o ponto de inflexão em Schiller, reaproximando razão e sensibilidade na construção de uma educação estética.

\section{As mônadas de Leibniz: a fonte ontológica do gosto na Alemanha}

A estética alemã, antes de atender por este nome, consolidou-se na base filosófica das mônadas de Gottfried Wilhelm Leibniz (1646-1716) Estas mônadas representariam unidades mínimas da realidade. Seu surgimento ou desaparecimento só podem ser dados por criação ou destruição; subsistem por si mesmas e nada de exterior pode lhes afetar a natureza. Consideradas unidades indivisíveis, devem ser tomadas em sua diversidade, pois observamos variadas formas e admitimos nada poder o exterior diante da natureza íntima destas estruturas. Vivemos num mundo em que se manifesta o diverso, o heterogêneo, o que leva Leibniz a crer que 
não são de unidades idênticas que se conforma a realidade, caso contrário tudo seria pura e simples homogeneidade. Essa ideia de multiplicidade o leva à outra consideração: as mônadas se modificam. Acontece que, como unidades indivisíveis, seria inadmissível que elas se modificassem ou fragmentassem por qualquer ação externa, sendo assim, as mudanças nas mônadas devem ser dadas por sua própria configuração interna; elas carregariam em si toda a sua existência passada, presente e futura; sua transformação estaria descrita em suas características e determinações. Leibniz chama de apetição essa potência interna de alteração das mônadas, melhor dizendo, o princípio capaz de gerar novas percepções, tomadas aqui como o "estado passageiro de manifestação" das unidades.

Assim, cada mônada seria dotada de uma potencialidade, contudo, na realização de suas potencialidades, elas esbarrariam nas potencialidades das outras mônadas, permitindo e gerando uma adequação e acomodação da realidade em função destas diferenças. Nessa perspectiva, cada mônada tem uma potencialidade máxima, só que, como são qualitativamente diferentes, manifestam-se não só em função de suas apetições internas, mas também em relação ao conjunto real de mônadas buscando sua realização. A despeito do argumento e retórica teológicos levados a cabo por Leibniz, essa reflexão filosófica conduz à necessária conclusão de que o mundo existente é o melhor dos mundos possíveis (o perfeito), pois é dado pelo máximo de potencialidade de cada mônada num contexto real, em que se manifesta não só a potência isolada, mas o conjunto existente de diferentes níveis e potencialidades. Em um mundo como esse é possível não só inferir o futuro das mônadas isoladamente, mas também o de seu conjunto, isso porque cada mônada isolada se relaciona com a totalidade de mônadas que determinam sua condição, sua existência.

Não devemos, equivocadamente, entender estas mônadas como propriedades estritamente materiais. Leibniz não as concebe desse modo, justamente porque seu poder e atuação se comunicam com aspectos racionais importantes. As mônadas, não sendo estritamente materiais, possuem graus diferenciados justamente em função destes níveis de 
percepção e apercepção (tomada consciente da percepção). É ainda por isso que existe uma superioridade das mônadas racionais sobre as demais; elas desempenham um caráter analítico e são capazes de compor, pela memória, o registro das outras mônadas, além de exercer seu poder e extensão sobre elas a partir da consciência de si. É desse modo que o princípio da razão suficiente impera sobre os demais, justamente por ser a operação racional mais elevada e, portanto, conduzir o conjunto das mônadas ao reino dos fins. É esta razão que toma consciência das apetições inerentes às mônadas e pode compreender como elas se articulam na consagração do mundo possível, que nada mais é do que a manifestação máxima de cada potência individual numa esfera de existência real, em que os graus diferenciados se sobrepõem e se limitam mutuamente. Cada unidade tende ao seu máximo, mas esbarra na realidade e existência de mônadas superiores, que lhes inibem o desenvolvimento ad infinitum.

Compreendidas estas fundamentações gerais, podemos esclarecer porque Leibniz é tão importante na construção estética alemã durante o século XVII e XVIII. A primeira consideração é sobre a percepção sensória, que, como podemos inferir da Monadologia, é concebida por Leibniz em um grau inferior à razão, dizendo respeito ao reconhecimento de sensações e à sua comparação. Logo, a atribuição de um valor a estas percepções é quase sempre injustificada, haja vista que não se sustentam em nenhum parâmetro racional de distinção. É assim que, falando das artes, Leibniz se expressa:

(...) nós, algumas vezes, vemos pintores e outros artistas julgarem corretamente o que tem, bem ou mal, sido feito; eles são, ainda, freqüentemente inábeis para dar uma razão para seu julgamento, mas fala o inquiridor que na obra que lhes desagradam falta alguma coisa, um não sei o que (LEIBNIZ apud GUYER, 2007, p. 04, trad. nossa)

A ideia de que falta algo à razão parece colocar a proposta de Leibiniz em complicação, indicando que haja uma mônada mais elevada no conteúdo representativo da realidade e no seu apoderamento diante das 
outras mônadas. A primeira ideia trabalhada por Wolff acerca do gosto a partir de Leibniz será, nesse sentido, a de que a percepção sensória fornece uma clara distinção e percepção das coisas, ainda que confusa, já que não pode fornecer uma exposição intelectual, racional para tais distinções. No entanto, Wolff não consegue ir muito longe, recuando no sentido de atribuir graus diferenciados para as percepções sensoriais, consideradas como sensações "que têm seu fundamento nas alterações dos membros de nossos corpos e que são ocasionados pelas coisas corpóreas fora de nós" (WOLFF apud GUYER, 2007, p. 06, trad. nossa), mas ainda submetidas à capacidade racional, cujas distinções produzem um conhecimento mais elevado do objeto do que uma representação ou percepção sensória deste. Na realidade Wolff encontra no próprio Leibniz uma saída para esta embaraçosa situação das mônadas: a ideia de perfeição.

A perfeição é a 'harmonia' ou 'concordância' de uma variedade ou multiplicidade de objetos ou partes de objetos. Esta simples consideração coloca a filosofia das mônadas de volta na sua posição central. A visão acabada do sistema ontológico de Leibniz seria a imagem perfeita da completude das relações de interação expressas no seu interior. A grandeza da realidade assim representada está na totalidade das mônadas em sua íntima relação potencial. O olhar total captaria, por fim, e ainda com o atributo da razão, a cena toda, o domínio geral do melhor mundo possível. Trata-se da harmonia do conjunto de mônadas existentes em sua busca pelo desenvolvimento individual das apetições internas em um cenário real de limitações externas. Através da ideia de perfeição, que é a concepção geral do sistema leibniziano, o debate estético ganha força, resgatando a ideia de totalidade como campo da contemplação estética da realidade. É assim, ao mesmo tempo, dependente das formas superiores de mônadas e da admissão das mônadas inferiores da sensibilidade, integradas na consideração geral do sistema mediante a ideia de perfeição.

\section{As consequências do olhar integrador}


A defesa de uma perfeição objetiva dos juízos de gosto ganhou espaço e, já no século XVIII, a resposta integradora do perfeito reaparece para consolidar a ideia de totalidade representativa das mônadas. Johann Christoph Gottsched (1700-1766) encontra na poesia este paralelo com Leibniz. A arte poética seria capaz de captar a imagem da totalidade sem recuar na direção do seu desmembramento. O caminho da palavra faria circular, num só tempo, a segmentação das partes com a reação (sensível e abstrata) harmônica de sua totalidade. Gottsched certamente reconhece o papel limitado da percepção e da sensibilidade, mas promove como central na discussão uma verdade invariável, a fonte perfeita pela qual se torna possível toda a representação e percepção sensorial. Tem, assim, "seu fundamento na natureza inalterável das coisas, em acordo com sua diversidade, ordem e harmonia." (GOTTSCHED apud GUYER, 2007, p. 12, trad. nossa). A partir deste invariável é que os juízos de gosto se estabelecem, eles brotam desta fonte inesgotável da totalidade na direção das partes. O fragmento poético possui a omniprontidão reveladora, ela capta e revela, ela fragmenta e se estende; a poesia é, acima de tudo, o ápice da representação artística e, neste lugar, transforma a ontologia herdeira de Leibniz e Wolff na categoria central do prazer ou da falta dele. Nesse sentido, a fórmula básica de produção ou reprodução do que agrada ou dá prazer está na captura da totalidade natural, cuja imitação artística encontra a beleza intrínseca à perfeição do mundo. A objetividade aqui se sustenta pela valorização de uma ordem geral de composição da arte através da imitação de uma perfeição inerente ao mundo.

Contudo, Alexander Baumgarten (1714-1762) é o primeiro que realmente inova no campo dos juízos estéticos. Seguindo as pistas da poesia de Gottsched, começa pela percepção sensível. Sua primeira tarefa é reconhecer aquilo que já fora dado por Wolff, quer dizer, que a percepção sensível tem como missão apropriar-se sensivelmente da perfeição mediante representações, logo, as representações mais elevadas são aquelas que fornecem uma imagem mais clara dessa perfeição do mundo: 
Nas representações obscuras não estão contidas representações suficientes de coisas conhecidas, com capacidade para reconhecer e distinguir o representado de tudo mais, mas se encontram nas representações claras (por definição); por conseguinte, estas, sendo claras, proporcionarão mais elementos para dar a conhecer as representações sensíveis que se fizeram obscuras. Assim, pois, um poema cujas representações são claras é mais perfeito do que outro cujas representações são obscuras, e as representações claras são mais poéticas que as obscuras. (BAUMGARTEN, 1955, p. 33, trad. nossa)

A dificuldade geral que se impõe a partir do que se conhece e se estabelece acerca das representações é que "as representações distintas, completas, adequadas, profundas em todos os seus níveis, não são sensíveis e, portanto, tampouco são poéticas." (BAUMGARTEN, 1955, p. 34, trad. nossa). A pergunta então é: como podem os sentidos inferiores, estes aparelhos sensíveis que promovem a percepção e fornecem os elementos para o juízo de gosto, indicar uma clara distinção na obtenção do prazer e na definição do que é ou não agradável? A resposta de Baumgarten é dada no funcionamento e no modo de operar da percepção antes da validade ou perfeição do conteúdo da representação. Para ele, os sentidos inferiores, aqueles responsáveis pela produção de representações sensíveis, operam em semelhança com a estrutura lógica da razão, quer dizer, possuem regras tão claras de assimilação e estímulos (prazerosos ou não) como qualquer regra estabelecida para a composição de conceitos. Suas Reflexões Filosóficas Acerca da Poesia tratam justamente de expor estas regras de associação entre representações sensíveis capazes de promover um estímulo agradável esteticamente, chamado então de poético, ou, ao contrário, de inibi-los. É como se Baumgarten estabelecesse aqui uma violação dos pressupostos leibnizianos de que somente a razão suficiente é capaz de conceber a máxima perfeição no mundo através da apercepção (tomada consciente da percepção). A distinção promovida pela lógica pode, como pretende provar Baumgarten, ser também alcançada mediante os sentidos inferiores; não neles mesmos, mas na sua forma de operar. 
A filosofia poética (...) é a ciência que dirige o discurso sensível à sua perfeição. Mas como nós ao falar temos estas representações que comunicamos, a filosofia poética supõe no poeta uma faculdade sensível inferior. Seria certamente tarefa da lógica, num sentido amplo, dirigir esta faculdade para o conhecimento sensível das coisas, mas quem conhece nossa lógica, chegaria de repente a reconhecê-la no estado atual das coisas?: Seria realmente ocasião de perguntar: será que a LÓGICA deverá reduzir-se aos estreitos limites que sua definição mesmo implica, considerando-a como uma ciência que trata de conhecer algo filosoficamente assim como uma faculdade cognitiva superior encarregada de dirigir-nos ao conhecimento da verdade? É claro que então se daria ocasião aos filósofos de buscar por seus meios, e com preciosa recompensa, artifícios que servissem para aperfeiçoar e aguçar suas faculdades inferiores de conhecimento, aplicando-as a si mesmo mas felizmente também em proveito de todos. Todavia, visto que a psicologia dá sólidos princípios, não duvidamos que possa se admitir proveitosamente uma ciência que dirija a faculdade cognitiva inferior para o conhecimento sensível das coisas. (BAUMGARTEN, 1955, p. 86, trad. nossa)

Fica estabelecido, assim, que "as coisas conhecidas o são por uma faculdade superior como objeto da lógica, do mesmo modo que as coisas percebidas hão de ser por uma faculdade inferior como seu objeto, ou pela Estética" (p. 87, trad. nossa). Por esse caminho, Baumgarten inaugura no debate estético alemão uma ciência com métodos próprios para a compreensão de como se dá a percepção das coisas e, o principal, como estas percepções se coadunam em princípios gerais capazes de uma teorização do gosto. Baumgarten servirá, por essa proposição, como base para o reconhecimento de uma atividade da mente na determinação do gosto, servindo de ponte para o estabelecimento dos juízos reflexivos de Kant, não sem antes revolucionar por completo a discussão estética na filosofia alemã.

Georg Friedrich Meier (1718-1777) dá continuidade a esta discussão, apontando, no entanto, uma valorização das paixões, elementos indissociáveis, segundo ele, da percepção geral do prazer e suas inclinações. Esta valorização das paixões na construção e estabelecimento dos juízos de gosto dizem respeito ao papel da imaginação no julgamento estético e, igualmente, do permeamento das emoções do sujeito no objeto julgado. De todo modo, e independente das influências, o que queremos salientar é o fato de que a emoção, em Meier, se torna agente principal nos juízos 
estéticos; é esta emoção que confere beleza ao objeto tomado sob julgamento do gosto. Estas emoções, por sua vez, se formariam na atividade da mente e, a partir delas, qualquer tema seria passível de representação e julgamento estético. Muito parecido com a valorização das operações gerais dos sentidos inferiores oferecida por Baumgarten, essa proposição de Meier fortalece dois ramos centrais no debate estético alemão da segunda metade do século XVIII: o papel da emoção no julgamento e representação dos objetos (Meier) e o da atividade da mente na produção dos juízos de gosto (Baumgarten).

Mas criando um contraponto, ou meio-termo na dupla via que se abre entre o reconhecimento da perfeição e da atividade da mente no debate estético alemão, Moses Mendelssohn (1729-1786) não considerava os juízos de gosto a partir de uma ou outra via isoladamente, mas como resultado de uma composição entre ambas, resgatando, assim, a discussão ontológica de Leibniz. Sua crítica é contundente ao falar de Baumgarten e Meier, ridicularizando, inclusive, a proposta deles ao colocarem em compasso a estética com a mera atividade da mente. Para Mendelssohn, esquecer do papel real, físico dos objetos que se dão ao juízo é uma pequenez de espírito e de investigação:

Somente sendo tão pequeno quanto um filósofo para poder descobrir a aparência da natureza sem exemplos da experiência, meramente através de inferências a priori; somente sendo tão pequeno pode ele estabelecer aparências no belo mundo, se alguém pode assim expressá-lo, sem observações diligentes. O caminho mais seguro de todos, exatamente como na teoria da natureza, é este: deve-se assumir certas experiências, explicar seus fundamentos através de hipóteses, então testar estas hipóteses contra experiências de espécies completamente diferentes, e somente então assumir estas hipóteses como princípios gerais, que têm assim assegurado seu fundamento; deve-se, finalmente, procurar explicar estes princípios na teoria da natureza através da natureza dos corpos e de seu movimento, não obstante em estética isso se dê através da natureza das faculdades inferiores de nossa alma. (MENDELSSOHN apud GUYER, p. 22-23, trad. nossa)

Ainda que mantenha o papel das faculdades ou sentidos inferiores na atribuição dos juízos estéticos, Mendelssohn não pode deixar de considerar 
que se tratam, sempre, de objetos estéticos reais, com características próprias, movimentos e operações naturais que minimamente devem ser concebidos e considerados em um exame acerca do gosto. $\mathrm{O}$ caráter central é não priorizar uma ou outra via, mas apoiar tanto na condição específica dos corpos representados como nas operações da mente a busca pela perfeição oferecida pela matriz Leibniz-wolffiana.

Tudo que é capaz de ser representado pelos sentidos como uma perfeição pode também ser um objeto de beleza. Pertencem aqui todas as perfeições das formas externas, isto é, as linhas, superfícies e corpos, seus movimentos e mudanças; a harmonia de múltiplos sons e cores; a ordem nas partes de um todo, suas similaridade, variedade e harmonia; suas transposição e transformação em outras formas; todas as capacidades de nossa alma, todas as habilidades de nosso corpo. Mesmo as perfeições de nosso estado externo (sobre os quais a honra, conforto e riqueza são as mais conhecidas) não podem ser excluídas destes se elas são formadas para ser representadas de um modo que é aparente para os sentidos. (MENDELSSOHN apud GUYER, 2007, p. 26 , trad. nossa)

É nessa dupla consideração da perfeição que Mendelssohn fornece os avanços na atividade da mente como essenciais na construção dos juízos estéticos. Ele consegue conceber essa aproximação porque se debruça sobre o campo espinhoso das faculdades de cognição e desejo. Como pretende considerar os objetos em sua realidade e movimento e, ao mesmo tempo, tratar da faculdade dos sentidos inferiores, a que se atribui usualmente o gosto, deve ele conceber que há aqui duas faculdades em ação: a de cognição, que capta os objetos em suas operações e movimentos, assim como em suas medidas e divisão; e a de desejo, promovida pelos sentidos inferiores. O gosto propriamente se daria em um jogo ou concordância destas duas faculdades, de modo que a estética seria o campo dessa interação. Assim, na consideração de um reconhecimento do perfeito por parte da cognição e do desejo, se estabelece ou se torna possível uma relação aberta entre a mente e o corpo, de tal sorte que:

(...) cada arrebatamento sensível, cada condição melhorada do gosto de nosso corpo, enche a alma com a representação sensível de uma perfeição, então toda representação sensível deve também, por sua 
vez, trazer com ela alguma coisa boa do corpo (...) E deste modo uma emoção prazerosa desperta. (MENDELSSOHN apud GUYER, 2007, p. 30, trad. nossa)

Segundo Guyer (2007) a emoção seria então processada no cérebro a partir de um "arrebatamento sensível" diante de um objeto, e, em consequência, transferiria igualmente para o corpo e para as representações da perfeição apreendida e processada como emoção. Como vemos, há em Mendelssohn tanto um avanço na consideração da emoção quanto da atividade da mente, embora divirja em larga medida de seus antecessores Meier e Baumgarten (ainda que adote muitos de seus fundamentos e com eles caminhe), sobretudo na valorização da discussão ontológica. A noção de um livre jogo das faculdades que começa a despontar em Mendelssohn e se difunde. Gotthold Ephraim Lessing (1729-1781) se apropriará justamente dela para explicar, em oposição a Johann Joachim Winckelmann (17171768), que a arte de representação da memorável obra grega Laocoonte está assentada nessa propriedade de livre jogo das faculdades e não no reconhecimento de uma verdade invariável e inabalável ou, em outras palavras, numa perfeição do objeto estético. Trata-se, para Lessing, de compreender uma tensão entre o momento da representação e o estímulo promovido em nossa imaginação pelo jogo das faculdades. O que encantaria na obra Laocoonte seria justamente esse tencionar, a tomada de uma cena que coloca os personagens em momentos distintos de aflição e dor, de maneira que o desfecho da história é preenchido e percorrido pela imaginação e as tendências que objetivamente se reconhecem e reciprocamente se apontam.

Estas reflexões chegam a segunda metade do século XVIII como extremamente problemáticas; a estética vagueia abertamente por territórios sombrios. Parte de sua tarefa parece afastar-se cada vez mais de um consenso geral e, experimentando os desvios, busca novamente uma unidade integradora, capaz de comunicar a atividade da mente com o fundamento ontológico de base, sem cair em dogmatismos. Quem desenvolverá solução de fato para a concepção de livre jogo das faculdades, 
servindo de fundamento para as investigações estéticas kantianas, será Johann Georg Sulzer (1720-1779).

Apoiado na teoria Leibniz-wolffiana, Sulzer considera que as faculdades de cognição e desejo são oriundas de uma fonte invariável, ou seja, trata-se de representações da perfeição real do conjunto das mônadas em seus diferentes graus de percepção. Não obstante, vai considerar, para além dessa base, o livre jogo das faculdades proposto por Mendelssohn. Para Sulzer, o prazer seria dado pelas representações mais claras e distintas da perfeição, seguindo Wolff, ao passo que estas se tornariam mais ou menos distintas justamente pela tarefa da mente de combinar livremente as faculdades na composição das representações. Assim é que a composição dele se liga à moral, já que pode pensar numa causa final ou em um invariável como fundamento do belo, ao tempo que pode e considera a atividade das representações no livre jogo das faculdades como esta passagem para o estabelecimento de juízos de gosto acerca do perfeito. É desse modo que a perfeição desperta o sentimento e o prazer estético, "seja por causa de seu material, por causa de sua forma externa, ou através de sua constituição interna, pelo seu significado de instrumento ou pelo pressuposto de alguma causa final." (SULZER apud GUYER, 2007, p. 52, trad. nossa).

Aqui, mostramos brevemente como Baumgarten, Meier, Mendelssohn e Sulzer realizam, a partir da matriz filosófica Leibnizwolffiana (por inspiração ou refutação), um debate estético importante na Alemanha, tendo como pontos principais a investigação ontológica e a atividade da mente (o livre jogo das faculdades) na consagração dos juízos de gosto. Este caminho percorrido pelos estetas alemães tenciona uma série de opiniões divergentes que carecem de uma sistematização final, uma solução para o impasse entre uma construção ontológica e o jogo das faculdades. Na verdade, Sulzer já se encaminha nessa direção, ressuscitando a ontologia de Leibniz e atribuindo a ela um livre jogo das faculdades no campo da representação. Essa aproximação será repensada por Kant com base em novos pressupostos filosóficos, fazendo referência ao projeto 
sistemático-filosófico-estético da Crítica do Juízo. Desse modo, o debate central estético da Alemanha, assim como se sucede com a discussão estética britânica, deságua na filosofia Crítica de Kant e, no que confere ao gosto, na formulação dos juízos reflexivos estéticos da sua Crítica do Juízo.

\section{A solução metafísica kantiana e o surgimento da estética moderna}

Antes de adentrarmos o debate estético kantiano propriamente dito, precisamos reforçar algo que esteve no centro da discussão, a concepção metafísica estrutural. Toda a investigação leibniziana propunha uma disposição sistemático-dogmática no apontamento da verdade a partir das mônadas. No entanto, tudo ocorria como se o terreno da investigação estética abandonasse as estruturas fundamentadoras da concepção de realidade expressa por Leibniz. Esta violação coloca na ordem do dia uma necessária discussão: como formas novas de pensar a questão estética não consolidaram uma nova composição metafísica? Vimos que as contraposições estéticas colocavam no centro das suas propostas a ideia de uma atividade da mente. Em certo sentido, e lançando o olhar um pouco adiante no que diz respeito à estética, veremos que ela só começa a ponderar novas possibilidades metafísicas na Crítica do Juízo de Kant. Mesmo a Crítica da Razão Pura, que traz introdutoriamente uma estética transcendental, não vai muito além dos limites colocados pelo ordenamento da razão e, ao que parece, não resolve de forma alguma a associação de uma atividade da mente com a valorização deste ou daquele objeto tomado esteticamente. A pergunta é: que aconteceu então?

Quando Kant propõe seu projeto Crítico, já tinha evidentemente consciência do debate estético alemão (e também britânico). De certo modo, permaneciam vivas as lembranças sistematizadoras de Leibniz, a despeito do sem número de críticas que a estética lhe impunha. As dúvidas e dificuldades que envolviam a apropriação do legado leibniziano das mônadas marcava a dificuldade analítica de uma metafísica capaz de 
incorporar a solução estética e, principalmente, dar conta de um debate teleológico em torno da fundamentação da natureza. Kant, após concluir suas duas primeiras Críticas vivia este embaraço, já que a sua primeira Crítica defendia apenas uma representação fenomênica do real mediante a faculdade do entendimento e, por outro lado, a imanência de um incondicionado da razão como centro de toda a finalidade humana do ponto de vista moral era comunicada através da Crítica da Razão Prática.

Mas eis que toma forma a Crítica da Faculdade de Julgar. Nela, Kant fala de uma outra classe de juízos, diferentes das duas primeiras críticas. Eles se consolidariam no vácuo que existe entre os juízos determinantes do entendimento e os juízos determinantes da razão pura prática. Essa faculdade de julgar, por estar entre entendimento e razão, e por não se ocupar nem com a simples intuição dos objetos nem exclusivamente das apetições do incondicionado, julga de uma maneira diferente das até então estabelecidas; não por uma legislação independente e própria, mas por uma forma diferente de "procurar leis". Chamam-se reflexivos justamente por serem dados a partir do particular e seu desdobramento, constituindo um meio termo entre o particular concebido e sob o qual se reflete e o universal para o qual tende. Estes juízos são, portanto, aqueles que não se dão por um a priori do sujeito transcendental e nem pelo objeto nele mesmo, mas pela faculdade de fornecer a si, por seu modo de operar como meio termo, princípios legislativos válidos, ainda que não determinantes. Se olharmos com atenção, perceberemos que a Crítica da Faculdade de Julgar não altera a construção metafísica das primeiras Críticas de Kant, quer dizer, ele mantém a dificuldade imposta pela razão na consideração da coisa-em-si, ainda sustentando a ideia de incondicionado e dos imperativos categóricos como caminho para uma livre compreensão do real. Com efeito, os juízos reflexionantes apresentados na sua Terceira Crítica apenas constituem uma forma diferente de representação. Sua universalidade ainda é dada pelo papel do entendimento que, mesmo que seja partícipe no reconhecimento e representação do objeto, não constrói o circuito de sua ligação empírica, substituindo-o pela atividade da faculdade de imaginação. Assim é que "O 
juízo de gosto é totalmente independente do conceito de perfeição", rompendo com a herança estética alemã e sua valorização de uma matriz filosófica apoiada em Leibniz. De acordo com Kant (1995): “...não existe nenhum argumento empírico capaz de impor um juízo de gosto a alguém." (p. 131). O princípio estético, ou a universalidade do gosto, é, como demonstramos, "o princípio subjetivo da faculdade do juízo em geral" (KANT, 1995, p. 133), ou seja, a sua forma de operar reflexiva. Aqui propriamente se unifica tudo o que estava disperso em oposição no debate estético alemão.

Ora, se a conformidade a fins da natureza tomada da forma é submetida ao livre jogo entre entendimento e imaginação na consagração de um juízo desinteressado, temos que os juízos estéticos são de uma conformidade a fins sem interesse objetivo, em outras palavras, uma conformidade a fins sem fim. Entendemos agora porque os juízos de gosto e os juízos teleológicos aparecem na mesma obra, justamente porque as respostas às dificuldades destes campos aparentemente distantes são dadas pela mesma faculdade, a de julgar. Está selada aqui, na Crítica do Juízo, a indissociável relação entre estética e teleologia da natureza; está explicado porque Kant recorre aos juízos de gosto, e mesmo inicia a terceira Crítica por eles, afinal, são os dilemas estéticos e todo o seu debate que conduzirão à resposta acerca da finalidade da natureza e de toda aparente contradição metafísica imposta pela consideração de uma causa final do e no mundo. Da mesma maneira, é pela forma natural em geral que se dá a produção do juízo estético pela ativação da faculdade de julgar, aparecendo então como conformação a fins sem um fim determinado pela razão. Poderíamos dizer até que os juízos reflexivos, herdados da perspectiva de atividade da mente de Baumgarten e de todo o desenvolvimento conceitual que lhe foi tributário no debate estético, foram fonte de salvação do sistema Crítico e, mais do que isso, a maneira eficiente de conceber uma natureza atuando segundo a fins sem um fim determinado da razão. A metafísica, problema básico da investigação estética, estava assim solucionada. 
Mas se prestamos a devida atenção, percebemos outro problema: a dualidade entre razão e sensibilidade. No final do século XVIII, a aparente indiferença entre estes dois domínios passou de mero distanciamento para um real embate e confronto. Tomando de assalto todas as dificuldades e limitações enfrentadas pela razão, a via da sensibilidade propõe uma nova forma de conceber e viver no e com o mundo. Nesse momento, a oposição entre razão e sensibilidade se traduz na contraposição pré-romântica à Aufklärung.

O movimento pré-romântico que encabeça esta mudança será chamado de Sturm und Drang (Tempestade e Ímpeto), o nome da peça teatral de Klinger. Ali havia muito do espírito da juventude, esse ultrapassar das barreiras impostas, sobretudo das regras de uma razão que limitaria a entrega a uma existência vivida, sentida para além de toda determinação; experimentada como o impulso de um povo, da natureza, na realização da vida. O valor da sensibilidade, compreendida aqui como o emergir sensível, aquilo que então se denominava os sentidos inferiores, é o reagir e o rebelar de um espírito novo, que nega uma pura especulação e produção analítica como reveladora dos sentidos e propósitos da existência. $\mathrm{O}$ fervor da paixão pueril é a marca desse ímpeto pelo sentimento, pela superação da razão ou seu nada poder diante da existência sensível. Os sofrimentos do jovem Werther retratam com maestria o fundamento geral dessa negação da pura abstração, do equilíbrio e controle da sensibilidade pelas regras da razão, culminando na entrega total, da própria vida, ao sentimento que ultrapassa em larga medida qualquer ponderação racional.

É propriamente aqui, na arte, que aparecerá a figura do gênio, cultuada no Sturm und Drang e elevada filosoficamente por Kant. Na sua visão o pressuposto de toda estética é seu desinteresse; a arte que se pretenda válida deve ser destituída de intencionalidade ou interesse, o que, em verdade, é impossível, uma vez que sua elaboração é motivada por um interesse do artista, ainda que seja seu propósito criar uma obra que represente o simples contemplar desinteressado. A resposta a esta dificuldade encontra então sua plena explicação na figura do gênio; é 
somente ele que pode produzir tal arte bela. Ele é o ser capaz de, na execução intencional da arte, reproduzir e criar um objeto que, de fato, não pareça intencional ou servir a qualquer propósito que não a apreciação estética; "isto é, a arte bela tem que passar por natureza, conquanto a gente na verdade tenha consciência dela como arte." O gênio é o ser dotado de um talento inato que não se orienta pelas regras acadêmicas, mas que em verdade as fundamenta e prescreve; é, antes de mais, fruto da natureza que, em última instância, dá a si mesma as regras de sua imitação e a possibilidade de reproduzir os prazeres e julgamentos estéticos na consagração da pura forma. A regra assim fornecida por ele não é nada além do que aquela disposta pela natureza através do dom genial. É assim tanto um produtor consciente direcionando a fins no seu projeto de arte, como o executor de um produto sem fim racional, meramente contemplativo, estético. Essa conformidade a fins sem fim é a representação do objeto da arte como síntese no particular do universal. Aquilo que é belo, prazeroso, nesse sentido, reagrupa na particularidade da forma a unidade geral do todo Absoluto, dito de outro modo, o belo é o particular cuja representação da forma revela a composição universal do todo.

\section{Da estética kantiana à educação estética de Schiller}

Percebemos de início que a estética schilleriana é herdeira de Kant, não só das contribuições expostas com a Crítica do Juízo no que diz respeito ao gosto, mas, sobretudo, na ligação das considerações estéticas com o incondicionado da razão pura prática, manifesta e representada pela ação moral. Schiller nos adverte sobre os dois extremos envolvidos na consideração do homem e, a partir deles, pensa a possibilidade de um equacionamento, uma forma de integração geral. Segundo Schiller, uma das considerações mais elementares e características da condição moral do homem é que, no que diz respeito a sua existência, tem sempre de conformar uma recusa de toda a multiplicidade, expressa nos fenômenos como casos particulares, agindo sempre, como advertira Kant na Crítica da 
Razão Prática, no uso imperativo da razão pura (prática). O dever moral, assim, representa a supressão formal de todo o particular mediante a universalidade do imperativo racional; no entanto, a vida do homem é ainda dada na esfera da multiplicidade, na esfera fenomênica, ou seja, no limite característico da sensibilidade. Há, na consideração moral herdeira de Kant, um sobrepor que tolhe no homem o seu caráter sensível, um exprimir formal de regras às quais toda especificidade de sua existência deve simplesmente ser negada no sentido estabelecido pela regra invariável, pelo dever.

Exatamente aqui, onde se procura equacionar a dualidade estabelecida entre razão e sensibilidade, apresenta-se o alvo central das advertências feitas ao projeto Crítico kantiano. A dualidade envolvida no incondicionado e a sobreposição deste em mão única na esfera fenomênica são o centro das controvérsias e marcam uma série de esforços sistemáticofilosóficos no final do século XVIII. A via proposta por Schiller é, no reconhecimento dessa dualidade, prescrever uma forma de associação, de recuperação da unidade cindida pelo imperativo da razão.

Mantida a dualidade, a princípio, temos de um lado o invariável da razão, o suprimir geral do tempo, que marca, segundo Schiller, o que a pessoa é, o formal de sua existência; do outro lado temos a variação temporalmente disposta como alternância de estado, como mudança permanente que preenche em conteúdo a mera forma. Razão e sensibilidade podem ser assim representados, de acordo com Schiller, como essa dupla condição: de ser o que é e, ao mesmo tempo, alternar-se indefinidamente, mudando o estado e as condições de todo o formal como invariável.

Pode-se inferir nessa caracterização do homem o que Schiller chama de dois impulsos distintos: o impulso sensível e o impulso formal. O impulso sensível é dado pela tendência geral do homem de envolver-se na esfera das sensações e deixar-se guiar pela dimensão do tempo, pela variação e alternância da entrega deleitosa no reconhecimento de uma matéria em transformação contínua. O impulso formal, por sua vez, procura o ultrapassamento livre de todo o particular; a supressão geral do tempo na consideração infinita. Trata, portanto, da esfera regulatória, que, em 
princípio, deve situar-se para o plano empírico como a determinação geral, a imposição geral a leis invariáveis e eternas. O seu pleno cumprimento é a perfeição.

Assim, na condição humana, divergente da concepção de um ser meramente racional e abstrato, impera de fato uma dualidade que, como tal, se reduz no homem sob a tarefa de "dar realidade ao necessário em nós e submeter a realidade fora de nós à lei da necessidade" (SCHILLER, 2002, p. 63). Quer dizer que a dualidade central é expressa sob a tarefa de elevar a sensibilidade e os particulares que lhe correspondem ao necessário expresso como imperativo e, doutra feita, fazer descer essa pura abstração da regra no mundo e tornar efetivamente prática a máxima invariável da razão.

Chegamos agora ao conceito de ação recíproca entre dois impulsos, em que a eficácia de cada um ao mesmo tempo funda e limita a do outro; em que cada um encontra sua máxima manifestação justamente pelo fato de que o outro é ativo.

Esta relação de reciprocidade entre os dois impulsos é meramente uma tarefa da razão, que o homem só está em condições de solucionar plenamente na perfeição de sua existência. É a Idéia de sua humanidade, no sentido mais próprio da palavra, um infinito, portanto, do qual pode aproximar-se mais e mais no curso do tempo sem jamais alcançá-lo. "Ele não deve empenhar-se pela forma à custa de sua realidade, nem pela realidade à custa da forma; deve, antes, procurar o ser absoluto pelo determinado e o determinado pelo absoluto. Deve contrapor-se um mundo por ser pessoa, e ser pessoa por se lhe contrapor o mundo. Deve sentir por ser consciente e ser consciente por sentir." O homem não pode experimentar a sua concordância com esta Idéia, com sua humanidade no sentido mais pleno, enquanto satisfaz exclusivamente um destes impulsos ou os dois sucessivamente: pois, enquanto apenas sente, fica-lhe oculta a sua pessoa, ou sua existência absoluta, e, enquanto apenas pensa, fica-lhe oculta a sua existência no tempo, ou seu estado. (SCHILLER, 2002, p.73) 
Schiller vivencia um momento bastante marcante da história moderna, a Revolução Francesa. Nesse sentido, consegue por um lado ver esse propósito geral de manifestação da liberdade no campo da prática, a consagração dos ideais no plano da mudança política. Todavia, essa Revolução, a princípio reverenciada como um avanço sem precedentes na forma de organização política e manifestação da liberdade, se transforma, aos seus olhos, num elevado grau de barbárie e sujeição dos mais altos ideais ao reboliço das massas ensandecidas. Essa visão afeta Schiller profundamente e, há esse tempo, deixa-lhe evidente o choque existente no homem; choque esse que deve ser sanado a fim de dirimir os excessos de um ou outro impulso. Safranski (2010) dirá que o jogo da arte será a chave central para a dissolução da dualidade e a acomodação adequada destes impulsos.

O jogo da arte estimula o homem a jogar com todas as suas forças - com a razão, o sentimento, a imaginação, a memória e a expectativa. Esse jogo livre liberta o indivíduo das limitações oriundas da divisão do trabalho. Permite a ele, que sofre por causa do esmigalhamento, tornar-se algo inteiro, uma totalidade menor, ainda que apenas no momento de tempo pré-estabelecido e na área limitada da arte. No prazer do belo, ele experimenta o gosto de uma plenitude que, tanto na vida prática quanto no mundo histórico, ainda estão por vir. (p. 46)

Para nos atermos à denominação do próprio Schiller na sua Educação Estética do Homem, identificamos, como solução ou mediação geral entre o impulso sensível e o impulso formal, o impulso lúdico. Este impulso mediador é justamente aquele responsável pelo jogo da arte, o jogo entre razão e sensibilidade. De um lado o impulso formal requer a supressão geral do tempo, requer o invariável, de outro, o impulso sensível pressupõe a alternância temporal, a mudança, portanto, o impulso lúdico estará “direcionado (...) a suprimir o tempo no tempo, a ligar o devir ao ser absoluto, a modificação à identidade" (SCHILLER, 2002, p. 74). Um tal impulso encontra sua forma de consagração e plena realização na 
consideração estética, na beleza. O belo é justamente esse confluir da alternância enquanto objeto fenomênico trazido então para a forma elevada, fixa, pela qual se estende a consideração e representação estética da natureza. Ainda em alusão a Kant, a ligação entre o objeto do impulso sensível, a vida enquanto natureza, e o objeto do impulso formal, o conceito, se dará sob a perspectiva de "forma viva" (SCHILLER, 2002, p. 77), a representação estética concebida sob o prisma da forma natural, só que desta feita ligada a um impulso lúdico e não como livre jogo entre entendimento e imaginação. O jogo agora é entre os impulsos contrapostos de razão e sensibilidade, intermediado e ligado sob o lúdico da "forma viva", a beleza.

A educação estética consiste aqui em direcionar o homem ao lúdico e, dessa forma, alcançar o equilíbrio que lhe é necessário. "Pela beleza, o homem sensível é conduzido à forma e o pensamento; pela beleza, o homem espiritual é reconduzido à matéria e entregue de volta ao mundo sensível" (SCHILLER, 2002, p.91). A arte aparece, em suas variadas formas, como a procura do meio-termo. Aquelas pessoas que se prendem ao impulso sensível devem se direcionar ao formal, ao contrário, aquelas ligadas à formalidade devem encontrar-se com o impulso sensível. Como não são plenamente suprimidos todos os limites e nunca cumprida a harmonia perfeita, resta a imagem da busca, a representação inacabada do ideal estético. Também ao artista cabe esse modelar, esse refazer-se de si. Os ligados aos impulsos sensíveis devem voltar-se ao formal, por outro lado, os envolvidos com o impulso formal, devem buscar a harmonia no impulso sensível. Esta é a medida da liberdade em Schiller e o valor da estética na educação. Segundo o próprio Schiller (2002): “(...) não existe maneira de fazer racional o homem sensível sem torná-lo antes estético.” (p. 113). Essa apresentação de um meio-termo, uma intermediação entre abstração e sensibilidade se deixa ver na própria tarefa de Schiller que, em carta a Goethe datada de 1796, se expressa da seguinte maneira:

Mas claro que essa atividade exige muito esforço, pois, se o filósofo pode deixar descansar o seu poder imaginativo, e o poeta, o seu poder de abstração, então eu, nessa forma de produção, preciso 
sempre conservar essas duas forças em igual intensidade, e somente através de um movimento contínuo em mim posso conservar os dois elementos heterogêneos numa espécie de solução. (GOETHE \& SCHILLER, 1993, p. 46-47)

É fundamental identificarmos aqui uma série de tendências e pressupostos que, partindo dessa "solução" de Schiller, seguirão como ponto central das considerações estéticas do romantismo. Em primeiro lugar há aquilo que reforçamos até o presente momento, uma ligação entre razão e sensibilidade, ou seja, a mera consideração teórica abstrata da Aufklarung é recusada, assim como a simples oposição a ela, como acontecia no ímpeto pré-romântico do Sturm und Drang. Delineia-se aqui um meio-termo entre razão e sensibilidade e, portanto, entre Aufklarung e Sturm und Drang. Em segundo lugar, ainda em consequência da primeira consideração, o impulso lúdico coloca a arte, a beleza, como meio-termo, como mediador universal e ponto central da síntese geral da realidade, do mundo, no homem. Residindo aqui a forma superior de educação do homem. Em terceiro lugar, a estética adentra a esfera do saber, ela se torna uma forma de conhecer ou conceber a realidade para além da mera consideração formal. A Educação Estética marca essa iniciativa de educar esteticamente o homem para que na sua construção histórica manifeste o mais elevado de sua natureza.

\section{CONSIDERAÇÕES FINAIS}

De uma maneira geral, pudemos ver que as considerações de Schiller dialogam diretamente com o legado kantiano e todo o debate estético do século XVIII. Como expusemos, o caminho kantiano nos juízos reflexivos era justamente expressar o valor estético saindo do particular para o universal, portanto, pode-se dizer que há, no Schiller aqui analisado, uma continuidade daquela solução kantiana para o estabelecimento do gosto. Ainda em conformação com Kant, pode-se dizer que o gênio, como produtor do belo na arte, é ao mesmo tempo a ligação geral entre razão e sensibilidade, visto que pode ele traçar um objetivo delimitado, racional, na 
execução da obra e, ao mesmo tempo, expressar espontaneamente, por sua natureza genial, um objeto aparentemente sem finalidade, a não ser contemplativa. Mas, embora tenhamos o central da concepção kantiana mantida, temos que esse exprimir do particular no universal e do universal no particular encontra uma nova consideração e ultrapassa a esfera da Crítica. O campo da estética deixou de ocupar uma estrita esfera teórica afeita às questões de prazer e desprazer para ligar agora o produto artístico e os juízos de gosto com o conhecimento acerca do mundo. Mais do que isso, apresentada como forma superior de conhecer, realizaria a arte o conhecimento supremo da essência sintética da realidade em constante oposição, para a qual o domínio estritamente racional nada podia isoladamente. Vimos desmoronar a contraposição que mantinha isolados a Aufklarung e o Sturm und Drang, no momento em que razão e sensibilidade se compuseram na arte como forma superior de existir e conhecer e na redefinição da razão a partir dos novos parâmetros românticos.

Saindo do debate estético nos séculos XVII e XVIII, passando pela filosofia Crítica de Kant e sendo redefinida na proposição de Schiller, a arte era união, o ponto de confluência de todo o desenvolvimento da humanidade em sua história; era a tensão no imediato da progressão infinita que transforma. Aquilo que a ocupa, o valor atribuído aos objetos, o sentido de todas as representações linguísticas e imagéticas guardam um novo significado, capaz de reintegrar tudo o que no conhecimento se apresentava em ruptura e de forma dispersa, dividida. Causas eficientes e causas finais, natureza e homem, encontram na ressignificação da arte um ponto de apoio, de síntese, que, para além de reunir em si uma composição meramente representativa, acaba por simbolizar a mais elevada forma de saber humano. Esse saber, estético-racional, é um saber que se vale da esfera abstrata, ao mesmo tempo em que a ultrapassa, atingindo a dimensão da vida, a forma de ser e existir no mundo e para com o mundo. Assim é que o valor do lúdico representa a ascensão de uma nova humanidade, a força média de um movimento que se estendeu, ganhou raízes até que sucumbiu, no longo século XIX, diante da recusa geral metafísica. O lugar de origem e a sua 
elevação final dimensionam o que se foi e, cansados do mesmo, podemos agora repensar parte desse legado perdido.

\section{REFERÊNCIA}

BAUMGARTEN, A. G. Reflexiones filosóficas acerca de la poesía. Trad. del latín, prólogo y notas José Antonio Miguez. Buenos Aires: Aguilar, 1955.

BENJAMIN, W. O conceito de crítica da arte no romantismo alemão. Trad. e notas Marcio Seligmann Silva. São Paulo: Iluminuras, 2002

BURKE. E. Uma investigação filosofica sobre a origem de nossas ideias do sublime e do belo. Tradução, apresentação e notas: Enid Abreu Dobranszky. Campinas: Papirus, 1993

GARBER, D. Leibniz: physics and philosophy. In The Cambridge Companion to Leibniz. San Diego: Cambridge University Press, 1998.

GOETHE \& SCHILLER. Companheiros de viagem: correspondências. São Paulo: Nova Alexandria, 1993.

GUYER, P. 18th century german aesthetics. In Stanford Encyclopedia of Philosophy, 2007.

KANT, I. Crítica da faculdade de julgar. Rio de Janeiro: Forense Universitária, 1995.

KANT, I. Crítica da razão pura. São Paulo; Nova Cultural, 1999 (Os Pensadores)

LEIBNIZ, G. W. A monadologia; Discurso de metafísica. São Paulo: Abril Cultural, 1979a, p. 101-152. (Os pensadores)

Filos. e Educ., Campinas, SP, v.11, n.1, p.156-182, jan./abr. 2019 - ISSN 1984-9605 
LESSING, G.E. Laocoonte ou sobre as fronteiras da pintura e da poesia: com esclarecimentos ocasionais sobre diferentes pontos da história da arte grega. Introdução, tradução e notas Márcio Seligmann-Silva. São Paulo: Iluminuras, 1998.

REGO, P. C. Reflexão e fundamento: sobre a relação entre gosto e conhecimento na estética de Kant. Belo Horizonte: KRITERION, no. 112, Dez/2005, p. 214-228.

SAFRANSKI, R. Romantismo: uma questão alemã. Trad. Rita Rios. São Paulo: Estação Liberdade, 2010.

SCHILLER, F. A educação estética do homem: numa série de cartas. Trad. Roberto Schwarz e Márcio Suzuki; Introdução e notas Márcio Suzuki. São Paulo: Iluminuras, 2002.

SULZER, J. G. Aesthetics and the art of musical composition in the german enlightnment: selected writings of Johann Georg Sulzer and Heinrich Christoph Koch. Edited by Nancy Baker and Thomas Christensen. Cambridge: Cambridge University Press, 1995, pp. 01-108.

Submetido em: 15/08/2019

Aceito em: 15/09/2019

Publicado em: 30/10/2019 